\title{
Combined reactive/non-reactive DC magnetron sputtering of high temperature composite $\mathrm{AlN}-\mathrm{TiB}_{2}-\mathrm{TiSi}_{2}$
}

\author{
A.V. Pshyk ${ }^{\mathrm{a}, \mathrm{b}, *}$, L.E. Coy ${ }^{\mathrm{a}, * *}$, L. Yate $^{\mathrm{c}}$, K. Załęski $^{\mathrm{a}}$, G. Nowaczyk ${ }^{\mathrm{a}}$, A.D. Pogrebnjak ${ }^{\mathrm{b}}$, S. Jurga ${ }^{\mathrm{a}}$ \\ a NanoBioMedical Centre, Adam Mickiewicz University, Umultowska 85, 61-614 Poznań, Poland \\ b Sumy State University, 2, Rymskogo Korsakova st., 40007, Sumy, Ukraine \\ c CIC biomaGUNE, Paseo Miramón 182, 20009 Donostia-San Sebastian, Spain
}

\section{A R T I C L E I N F O}

\section{Article history:}

Received 23 September 2015

Received in revised form 29 December 2015

Accepted 31 December 2015

Available online 3 January 2016

Keywords:

Hard coatings

Nanocomposite

Functionally graded film

Nanoindentation

Wear test

\begin{abstract}
A B S T R A C T

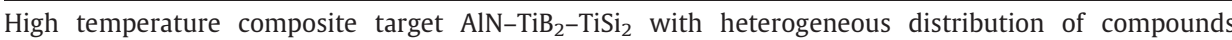
(AlN-50 wt.\%; $\mathrm{TiB}_{2}-35$ wt.\%; $\mathrm{TiSi}_{2}-15 \mathrm{wt} . \%$ ) is used for sputtering via combined reactive/non-reactive DC magnetron sputtering onto substrate materials either cylindrical polished steel ( $\mathrm{Fe}, 18 \%-\mathrm{Ni}, 12 \%-\mathrm{Cr}, 10 \%-\mathrm{Ti}) 3 \mathrm{~mm}$ diameter or monocrystalline silicon. The gradient coating has been produced by sequential non-reactive and reactive sputtering of the target. The structural and morphological properties of the deposited films are analyzed by transmission electron microscopy, scanning electron microscopy, atomic force microscopy, X-ray photoelectron spectroscopy and Raman spectroscopy. The tribo-mechanical properties are studied by means of nanoindentation and nanowear tests. The gradient film is composed of two layers with different microstructure and elemental composition. The first layer with thickness $\sim 200 \mathrm{~nm}$ is mainly based on light B, C and N as well metal elements Al, Si and Ti. The presence of very well distributed nanocrystals embedded in an amorphous matrix, with crystal sizes ranging from 5 to $40 \mathrm{~nm}$ is observed in the second layer $700 \mathrm{~nm}$ thickness and composed of $\mathrm{Al}, \mathrm{Ti}, \mathrm{Si}, \mathrm{B}$, and N. Films show very flat surfaces, with roughness around $0.35 \mathrm{~nm}$. The hardness, elastic modulus, elastic recovery $\left(\mathrm{W}_{\mathrm{e}}\right), \mathrm{H} / \mathrm{E}^{*}$ ratio and $\mathrm{H}^{3} / \mathrm{E}^{* 2}$ ratio are determined as $17.55 \mathrm{GPa}, 216.7 \mathrm{GPa}, 60 \%, 0.08$ and $0.12 \mathrm{GPa}$, respectively. Nanowear tests demonstrate relatively high wear resistance of the coatings. Samples show promising characteristics for hard protective adaptive coatings and diffusion barriers due to short propagation of dislocations in the amorphous matrix and the elastic and hard nature of the nanocomposite structure.
\end{abstract}

(c) 2016 Elsevier Ltd. All rights reserved.

\section{Introduction}

Protective nanostructured coatings have applicability as universal multifunctional materials with high tribological performance [1-4]. One the most promising materials are the so called nanocomposite coatings, that have demonstrated ultrahigh hardness ( $\geq 100 \mathrm{GPa}$ ) as well as oxidation resistance at $\geq 1000{ }^{\circ} \mathrm{C}[5,6]$. Nevertheless, such types of composites are incapable of preventing failure of the coating, especially in the case of cutting tools, when the surface undergoes severe and continuous damage [7]. Moreover, nanocomposite coatings have low coefficient of friction at high temperatures [8]. Therefore, the real multifunctionality of these coatings is still an open question, because it is not clearly seen, which combination of properties (high temperature friction coefficient, wear resistance, oxidation resistance, etc.) would let them to undergo different operation conditions during exploitation in

\footnotetext{
* Correspondence to: A. V. Pshyk, NanoBioMedical Centre, Adam Mickiewicz University Umultowska 85, 61-614 Poznań, Poland.

** Corresponding author.

E-mail addresses: a.v.pshyk@gmail.com (A.V. Pshyk), coyeme@amu.edu.pl (L.E. Coy).
}

aggressive environment and high temperatures. On the other hand, multilayered coatings may have lower hardness, but possess enhanced wear resistance properties $[9,10]$. Such type of nanostructured coatings exhibit adaptive behavior during operation through generation of tribofilm on the friction surface, that allows protecting and lubricating the surface and, as a result, allows decreasing of the wear rate [11].

One alternative, addressing the aforementioned issues, is the engineering of protective nanostructured coatings, by the integration of both, multilayered and nanocomposite approaches. In such a way, characteristics of the systems are interconnected in order to reach the desired multifunctionality and adaptive behavior [12].

One of the types of such integrative approach in the field of protective coatings is the gradient nanostructured coatings [13,14]. Gradient coatings are either composite or single phase coatings in which their functional properties change uniformly or unevenly at least in one direction. The changes in the functional properties of gradient coatings are achieved through continuous variation of elemental composition and microstructure with the depth of the coating. The main ways of practical application of the gradient coatings are materials and tools which undergo high gradients of mechanical forces as well as temperatures [15]. 
Therefore, it is possible to combine complex functional properties, such as high hardness, corrosion resistance, high-temperature oxidation resistance and wear resistance, in one coating using the concept of gradient coatings.

Nevertheless, the search and investigation of novel models of universal high-performance coating is a hot topic in both the academy and the industry today. It is well-known that composition and structure of a film and, consequently, its properties, are controlled via adjusting of deposition parameters of the magnetron such as applied voltage to the target, applied bias on the substrate, substrate temperature, target to substrate distance, working gas pressure and flow rate etc. [3,16-19]. Our approach is then based on combining non-reactive/reactive DC magnetron sputtering of a composite target with the aim to synthesize gradient coatings with high $\mathrm{N}$ content on the top surface layer.

High-temperature ceramics $\mathrm{AlN}-\mathrm{TiB}_{2}-\mathrm{TiSi}_{2}$ [20], which combine excellent physical-mechanical properties, are a perspective material for producing protective coatings with a large variety of properties.

Therefore, the goal of this work is to provide comprehensive investigation of gradient protective coatings fabrication via DC magnetron non-reactive/reactive sputtering of high-temperature ceramic AlN$\mathrm{TiB}_{2}-\mathrm{TiSi}_{2}$ target as well as the analysis of their microstructure and mechanical properties.

\section{Experimental details}

High-temperature ceramic $\mathrm{AlN}-\mathrm{TiB}_{2}-\mathrm{TiSi}_{2}$ target was sputtered via DC magnetron sputtering on steel and Si (001) substrates. Substrates were cleaned in Ar plasma discharge during 15 min prior to deposition. High-temperature ceramic $\mathrm{AlN}-\mathrm{TiB}_{2}-\mathrm{TiSi}_{2}$ target $70 \mathrm{~mm}$ in diameter and $40 \mathrm{~mm}$ thickness was synthesized from a powder mixture of AlN (50 wt.\%), $\mathrm{TiB}_{2}$ (35 wt.\%) and $\mathrm{TiSi}_{2}$ (15 wt.\%) by hot isostatic pressing at $1860-1880{ }^{\circ} \mathrm{C}$ in air. The residual porosity of the target did not exceed $2 \%$. The discharge power is supplied from a stabilized DC power unit ( $400 \mathrm{~V}, 7.7 \mathrm{~A}$ ) working in the voltage-regulated mode. The deposition was performed at room temperature using the following parameters of DC magnetron: discharge current $\sim 200 \mathrm{~mA}$, cathode-substrate distance was $65 \mathrm{~mm}$. A negative DC bias of $100 \mathrm{~V}$ was applied to the samples during whole deposition process. In order to produce gradient composition of the coating the deposition started in non-reactive mode with $\mathrm{Ar}$ gas partial pressure $0.078 \mathrm{~Pa}$ for $60 \mathrm{~min}$. Then the target was sputtered in gas mixture of argon and nitrogen in amount $5 \% \mathrm{~N}_{2} / \mathrm{Ar}$. The nitrogen-to-argon ratio and working gas pressure at $\sim 0.078 \mathrm{~Pa}$ were kept constant during next 35 min of deposition.

The morphology and structure of coating's surface were studied using atomic force microscope Bruker Dimension Icon. The microstructure and elemental composition of coatings were examined by scanning electron microscope (SEM) JEM-7001TTLS, JEOL and transmission electron microscope (TEM) ARM-200F, JEOL. The preparation of crosssectional samples for TEM was carried out using focused ion beam system JIB-4000, JEOL with $\mathrm{Ga}^{+}$ions. Thin carbon film was deposited prior to ion etching in order to prevent sample damage.

$\mathrm{X}$-ray photoelectron spectroscopy (XPS) was performed in a SPECS Sage HR 100 spectrometer with a non-monochromatic X-ray source ( $\mathrm{Al} \mathrm{K \alpha}$ line of $1486.6 \mathrm{eV}$ energy) at $300 \mathrm{~W}$ and calibrated using the $3 \mathrm{~d}_{5 / 2}$ line of Ag with a full width at half maximum (FWHM) of $1.1 \mathrm{eV}$. The selected resolution for the high-resolution spectra was $15 \mathrm{eV}$ of Pass Energy and $0.15 \mathrm{eV} / \mathrm{step}$. All measurements were made in an ultra-high vacuum (UHV) chamber at a pressure around $8 \times 10^{-8}$ mbar. The etching of the samples was done with $\mathrm{an}^{+}{ }^{+}$beam with energy of $3 \mathrm{kV}$ at several times.

The Raman spectroscopy was performed using Renishaw inVia confocal Raman microscope with $633 \mathrm{~nm}$ laser wavelength. The spectra were recorded with 50\% laser power, 8-9 accumulations and exposition set at $10 \mathrm{~s}$.

The measurements of hardness $(\mathrm{H})$ and reduced elastic modulus $\left(E^{*}\right)$ were carried out by load-depth-sensing nanoindentation method using a Hysitron TriboIndenter 950 equipped with Berkovich diamond pyramid TI-0039 (conical angle $142.3^{\circ}$ and $100 \mathrm{~nm}$ tip radius) calibrated against fused silica. To measure hardness $(\mathrm{H})$ and reduced elastic modulus $\left(E^{*}\right)$ of coatings at different depths a multiple load function (trapezoidal sinus form) was applied to the indenter. The load was changed step-by-step starting from $0.05 \mu \mathrm{N}$ to $10 \mathrm{mN}$ (a segment of load lasted $-3 \mathrm{~s}$, holding segment $-0.5 \mathrm{~s}$ and unloading $-3 \mathrm{~s}$ ).

\section{Results and discussion}

\subsection{Scanning electron microscopy-energy dispersive spectroscopy studies}

The micrograph (Fig. 1) shows a fracture cross-section SEM of the coating, which exhibits a dense and plain structure. The coatings show no porosity or delaminations, which suggest good adhesion to a technically important substrate such as steel. The coatings were stable in ambient air for several months after deposition with no signs of hydrolysis or delamination.

\subsection{Atomic force microscopy studies}

The coating surface was characterized using atomic force microscopy (AFM). From AFM images, a quantitative assessment of the surface roughness can be made. The AFM images (Fig. 2a and b) as well as results of roughness measurements (Fig. 2c) showed that TiAlBSiN coating surface is smooth with nanoscale roughness, $R a=0.38 \mathrm{~nm}$. Such nanoroughness is indicative of the good quality of the coatings produced by DC magnetron sputtering of the composite targets. The multiscale roughness (micro- and nanoroughness) formed after DC magnetron sputtering on the surface of the protective coating is an important structural part of the coating on tools, which could undergo both different friction conditions and temperature impact during operation.

\subsection{Transmission electron microscopy-energy dispersive X-ray spectroscopy studies}

The microstructure and the qualitative elemental composition of the thin cross-section of the TiAlBSiN coating were investigated via TEM with EDS analysis. According to cross sectional view EDS mapping (Fig. 3 ) in depth element distribution is not homogenous. It is clearly seen that TiAlBSiN coating consists of two layers with different

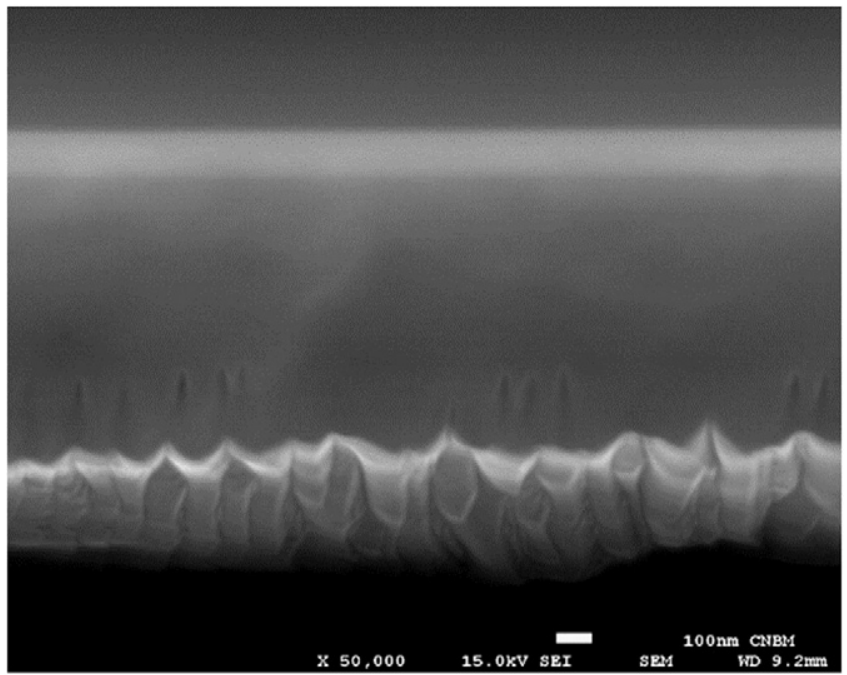

Fig. 1. Secondary electron cross-section image of TiAlBSiN coating. 


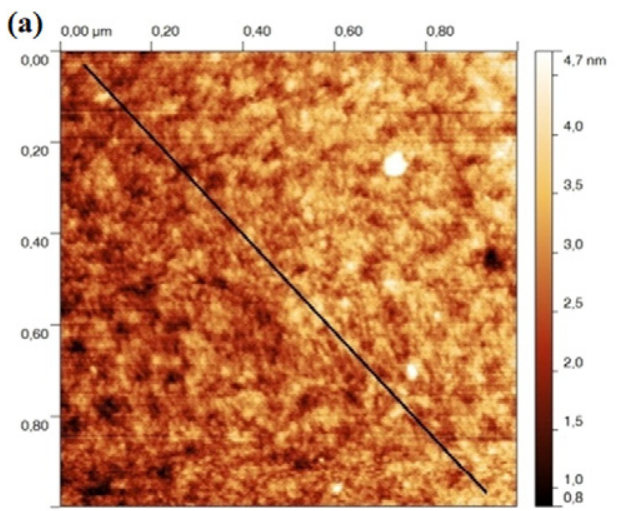

(b)

(c)

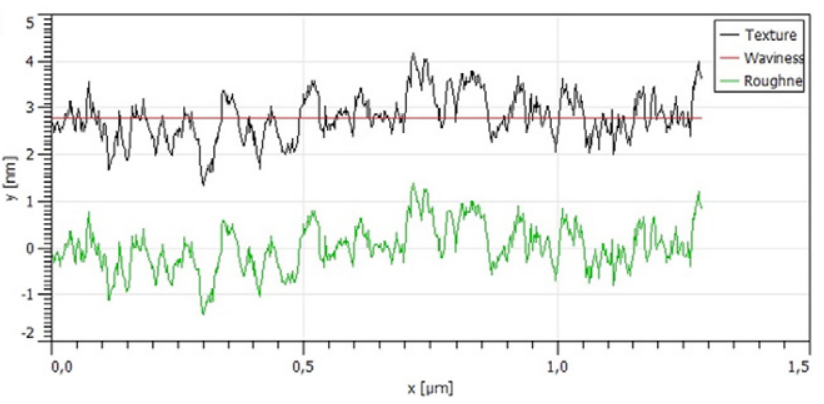

Fig. 2. AFM $1 \times 1 \mu \mathrm{m} 2 \mathrm{D}(\mathrm{a})$ and 3D (b) topography images of TiAlBSiN coating surface and line profile of nanoroughness on $1297 \mu \mathrm{m}$ length (c).

elemental composition and microstructure. As it is observed in Fig. 3, the top layer (L1) is mainly composed of light elements N, B, C and $\mathrm{O}$ while base composition of the bottom layer (L2) consists of heavier elements $\mathrm{Al}$, Ti and Si. It is important to note a diffusion of Fe from the substrate to the coating that could stimulate additional phase transformations in the coating and making the interpretation of the results more difficult.
Fig. 4a and b presents the L1 and L2 structures of the TiAlBSiN coating at a higher magnification. The top layer of about $220 \mathrm{~nm}$ in thickness (L1) shows fine crystallites with dimensions in the range of 15-40 nm. L2 is formed by nanograins, which are almost non-uniformly distributed with a relatively wide size distribution of about 5 to $40 \mathrm{~nm}$. An amorphous matrix in which the grains in L1 and L2 are embedded is well visible and confirmed by HRTEM images (Fig. $5 a$ and b). A filtered imaged, (b)

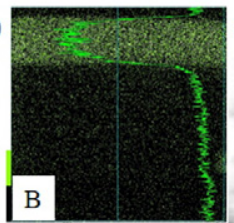

(c)

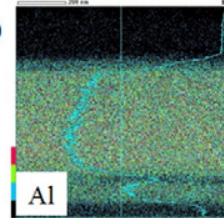

(d)

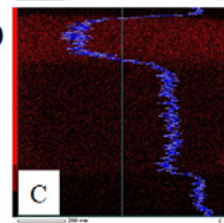

(e)

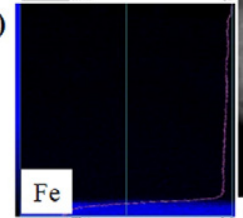

(a)
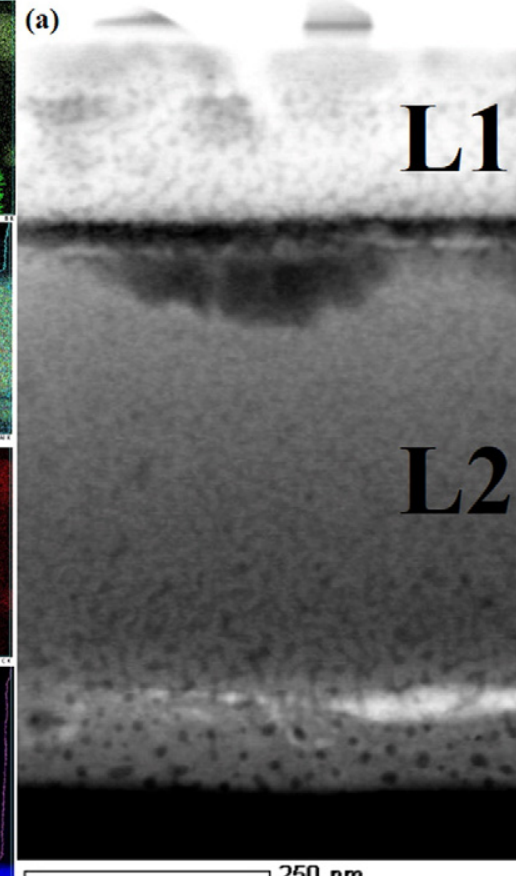

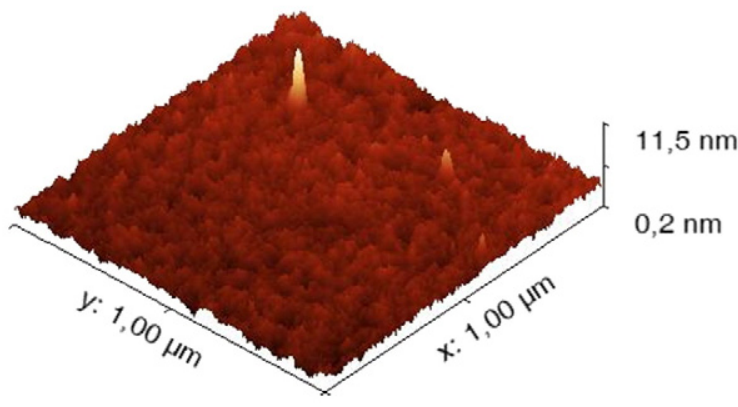




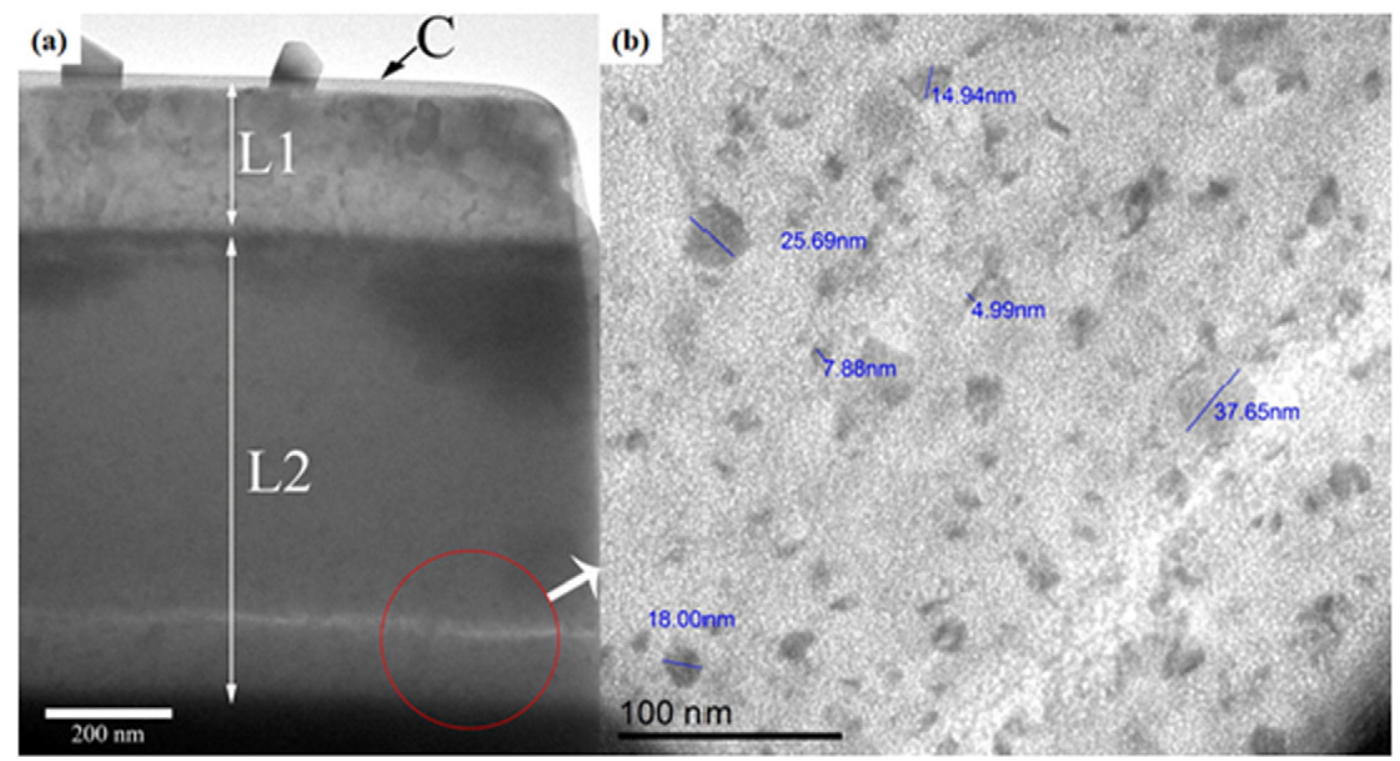

Fig. 4. Cross-sectional bright field TEM micrographs of the TiAlBSiN coating (a). The circle indicates the field shown at higher magnification in (b).

obtained by using the most intense peaks observed in the fast-Fouriertransform (FFT) extracted from the HRTEM micrographs, allows to clearly visualize the crystalline and amorphous boundaries. It is important to mention that the crystalline indexation of the peaks is used to both comprehend the broad range of possible composition on the coating and give a clear perception of the $\left(\mathrm{Al}_{\mathrm{x}} \mathrm{Ti}_{1}-\mathrm{x}\right)\left(\mathrm{O}_{\mathrm{y}} \mathrm{N}_{1-\mathrm{y}}\right)$

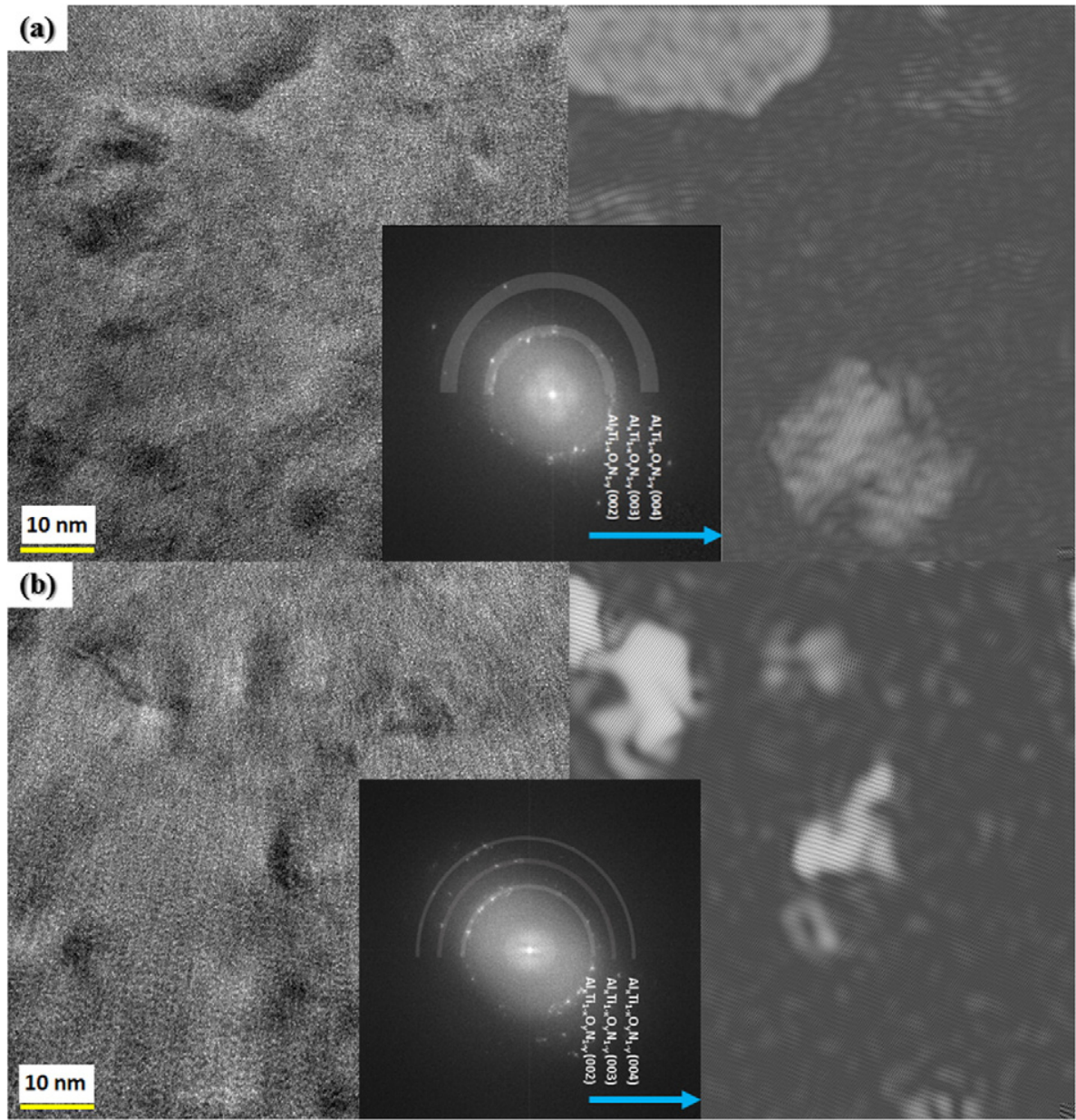

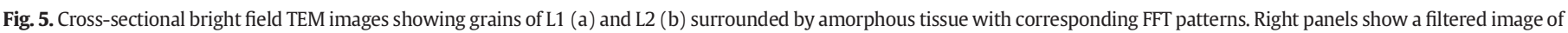
the most intense peaks of in the FFT image, clearly showing the grains within the coating. 
crystals embedded in the coatings. These studies clearly show a phase separation between crystalline and amorphous phases that take place during the coating growth, giving place to the nanocomposite coating structure in both layers.

\subsection{X-ray photoelectron spectroscopy studies}

XPS was carried out in order to obtain additional information about quantitative elemental composition and chemical binding states of the coating. The element depth profile of TiAlBSiN coating is presented in Fig. 6. A two-layer structure is clearly observed for the TiAlBSiN coating which is in agreement with the SEM-EDS studies mentioned above (Fig. 3). L1 is characterized by high concentration of light elements and the presence of $\mathrm{Al} \sim 20$ at.\%. It is important to note that $\mathrm{N}$ and $\mathrm{O}$ have a nonuniform distribution through the depth of the L1. The stepwise changing of elements concentration is observed close to the interface $\mathrm{L} 1 / \mathrm{L} 2$ : concentrations of $\mathrm{O}, \mathrm{C}, \mathrm{Al}, \mathrm{B}$ are increasing while $\mathrm{N}$ and $\mathrm{Ti}$ are decreasing. The atomic concentration of $\mathrm{Ti}, \mathrm{Al}$, and $\mathrm{B}$ increases while concentration of $\mathrm{O}, \mathrm{N}$, and $\mathrm{C}$ decreases in the L2, demonstrating homogenous distribution with increasing of the sputtering time. The bulk composition of the L1 was determined to be nonstoichiometric $\mathrm{Ti}_{0.09} \mathrm{Al}_{0.21} \mathrm{~B}_{0.16} \mathrm{Si}_{\mathrm{x}} \mathrm{N}_{0.22} \mathrm{C}_{0.14} \mathrm{O}_{0.18}$ and for $\mathrm{L} 2$ $\mathrm{Ti}_{0.11} \mathrm{Al}_{0.25} \mathrm{~B}_{0.23} \mathrm{Si}_{\mathrm{x}} \mathrm{N}_{0.17} \mathrm{C}_{0.11} \mathrm{O}_{0.13}$. Although silicon is present in the coatings, the total concentration of $\mathrm{Si}$ was not determined because of the overlapping of the Si 2 p spectrum with the Auger KLL line of Al.

Presented distribution of elements over the depth of the TiAlBSiN coating is defined by the characteristic of sputtering processes of a multiphase target, as well as by the specific behavior of the reactive DC magnetron sputtering [21]. The distribution of elements and phases over the depth in the target is also very important, and it is considerably defined by the fabrication process of the target by the hot isostatic pressing of powders. Thus, the target contained the following phases after sintering [22]: $\mathrm{TiB}_{2}, \mathrm{AlN}, \mathrm{TiN}, \mathrm{TiSi}_{2}, \mathrm{Si}_{3} \mathrm{~N}_{4}$ and $\mathrm{Al}_{2} \mathrm{O}_{3}$ that along with different crystallographic orientation and distribution of these phases over the depth of the target strongly influence the value of the coefficient of sputtering. This process leads to preferential sputtering of the component with higher yield and the sputtered flux is rich in this constituent. Consequently, the L1 coating is enriched with the material having the highest sputtering yield. Moreover, the difference in composition of L1 and L2 can be explained by the injection of $\mathrm{N}_{2}$ during deposition of L1. It is well known $[3,21]$ that the decrease in deposition rate of films sputtered in the reactive mode is due to a reaction of the reactive gas with the surface of the sputtered target and the formation of different additional compounds on its surface. This results in decrease of sputtering yield and magnetron discharge voltage, $U_{\mathrm{d}}$.

Because of the irregularity of the target and the injection of $\mathrm{N}_{2}$ to the working gas, local areas with different elemental concentration are observed and the two layers in the TiAlBSiN coating were formed. The contents of all metal elements in the coating are the same as in the target. Noticeably, the presence of $0 \sim 17$ at.\% in the L1 and $\sim 12$ at.\% in the L2 layer, which can be explained by to the low deposition rate and presence of $\mathrm{O}$ in the target. The $\mathrm{O}_{2}$ source in the coating is still undefined [24]; however, the following sources were suggested: the residual gas and plasma or heating-induced desorption from the deposition chamber or $\mathrm{O}$ containing phases in the target. Because of the very low deposition rate, the $\mathrm{O}_{2}$ can be incorporated in the growing coating more readily [25].

Typical Ti 2p, N 1s, O 1s, B 1s and Al 2p XPS spectra of the L1 layer of the TiAlBSiN coating are presented in Fig. 7. The Ti 2p spectrum (Fig. 7a) presents a broad and asymmetrical Ti $2 \mathrm{p}_{3 / 2}$ and $\mathrm{Ti} 2 \mathrm{p}_{1 / 2}$ doublets. The Ti $2 \mathrm{p}$ spectrum was fitted into 3 spin-orbit doublets, in which the Ti $2 \mathrm{p}_{3 / 2}$ peak position at around $455.5 \mathrm{eV}$ fitted with an asymmetric shape is attributed to Ti-N bonds [26]. Some amount of bonds attributed to $\mathrm{Ti}_{2} \mathrm{O}_{3}$ and $\mathrm{TiO}_{2}$ with the $\mathrm{Ti} 2 \mathrm{p}_{3 / 2}$ peak positions at around 457.4 and $458.8 \mathrm{eV}$ [27], respectively, are also found.

The $\mathrm{N} 1 \mathrm{~s}$ spectrum can be fitted with two peaks (Fig. 7b). The most intense peak can be attributed to $\mathrm{Si}-\mathrm{N}$ or Ti-N bonds $(397.5 \mathrm{eV}$ ) as reported for $\mathrm{Si}_{3} \mathrm{~N}_{4}$ [27] and TiN [28]. The other peak with lower intensity can be assigned to $\mathrm{C}-\mathrm{N}$ bonds (399.3 eV) [27][ref].

The $\mathrm{O} 1 \mathrm{~s}$ spectrum (Fig. 7c) shows one main component at around $531.8 \mathrm{eV}$ which can be attributed to $\mathrm{Al}-\mathrm{O}$ bonds in $\mathrm{Al}_{2} \mathrm{O}_{3}$ [27]. The $\mathrm{B} 1 \mathrm{~s}$ spectrum can be fitted with three components, Fig. 7d. The main component at around $191.2 \mathrm{eV}$ can be associated to B-N bonds [29]. Other minor components at around 188.3 and $193.3 \mathrm{eV}$ can be associated to Si-B [27] and B-O bonds [27], respectively.

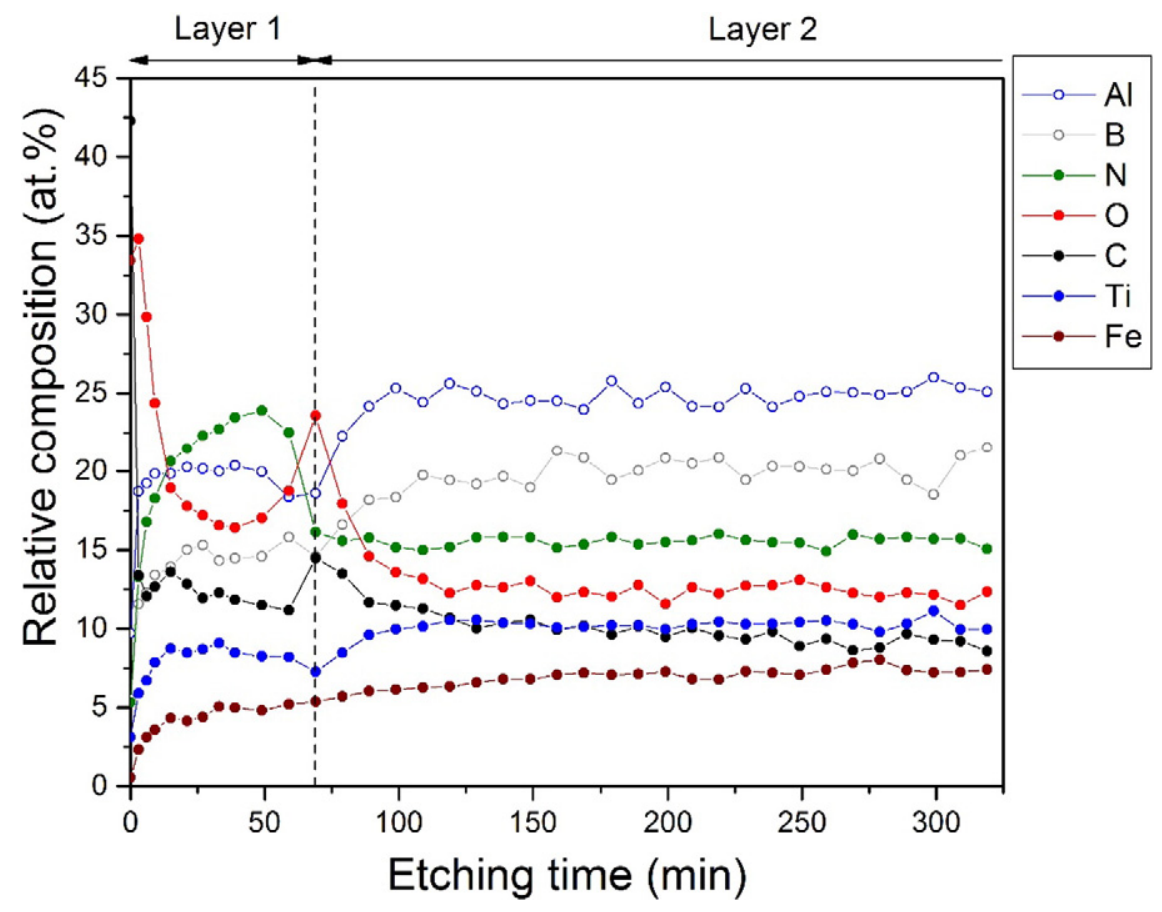

Fig. 6. XPS depth profile of the TiAlBSiN coating. 

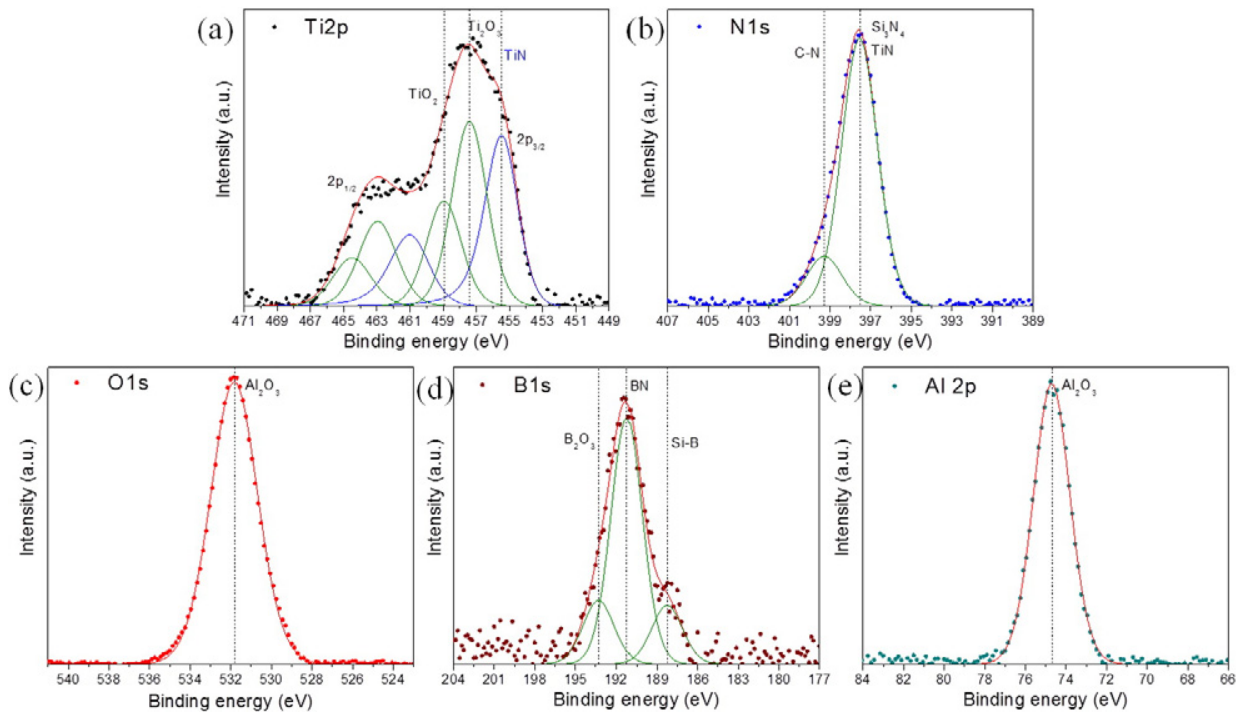

Fig. 7. XPS spectra of the layer L1 of the TiAlBSiN coating.

Fig. 7e shows the fitted $\mathrm{Al} 2 \mathrm{p}$ spectrum. Only one peak can be fitted at around $74.7 \mathrm{eV}$ as reported for $\mathrm{Al}_{2} \mathrm{O}_{3}$ [27]. The XPS analysis led to the conclusion that the TiAlBSiN coating is mainly composed of Ti-N, Ti-O, Al-O, B-N, B-Si and B-O bonds which could be attributed to TiN, $\mathrm{Ti}_{2} \mathrm{O}_{3}, \mathrm{TiO}_{2}, \mathrm{Al}_{2} \mathrm{O}_{3}, \mathrm{BN}, \mathrm{SiB}_{3}$ and $\mathrm{B}_{6} \mathrm{O} / \mathrm{B}_{2} \mathrm{O}_{3}$, respectively. The chemical mixing enthalpy of $\mathrm{Al}_{2} \mathrm{O}_{3}\left(-1675.7 \mathrm{~kJ} / \mathrm{mol}^{-1}\right)$, $\mathrm{Ti}_{2} \mathrm{O}_{3}\left(-1520.9 \mathrm{~kJ} / \mathrm{mol}^{-1}\right), \quad \mathrm{TiN}\left(-265.8 \mathrm{~kJ} / \mathrm{mol}^{-1}\right), \quad B N$ $\left(-254.4 \mathrm{~kJ} / \mathrm{mol}^{-1}\right)$ and $\mathrm{B}_{6} \mathrm{O}\left(-1244.5 \mathrm{~kJ} / \mathrm{mol}^{-1}\right)$ [30] is very high and negative. These results evidence the formation of such systems during the deposition of the thin film. The very close values of enthalpy for $\mathrm{Al}_{2} \mathrm{O}_{3}, \mathrm{~B}_{6} \mathrm{O}$ and $\mathrm{Ti}_{2} \mathrm{O}_{3}$ as well as TiN and $\mathrm{BN}$ could led to the formation of a solid solution between $\mathrm{Al}, \mathrm{B}, \mathrm{Ti}$ and $\mathrm{O}, \mathrm{N}$. The high concentrations of $\mathrm{O}$ and $\mathrm{Al}$ at the interface of the $\mathrm{L} 1$ and $\mathrm{L} 2$ have caused the formation of a thin $\mathrm{Al}_{2} \mathrm{O}_{3}$ diffusion barrier against mass transport, which can play an important role in high temperature stability of the coating.

\subsection{Raman studies}

The Raman spectrum of the TiAlBSiN coating is shown in Fig. 8. The spectrum of the coating shows broad bands centered at $240 \mathrm{~cm}^{-1}$ and low intense bands centered at $482 \mathrm{~cm}^{-1}$. These bands originate from

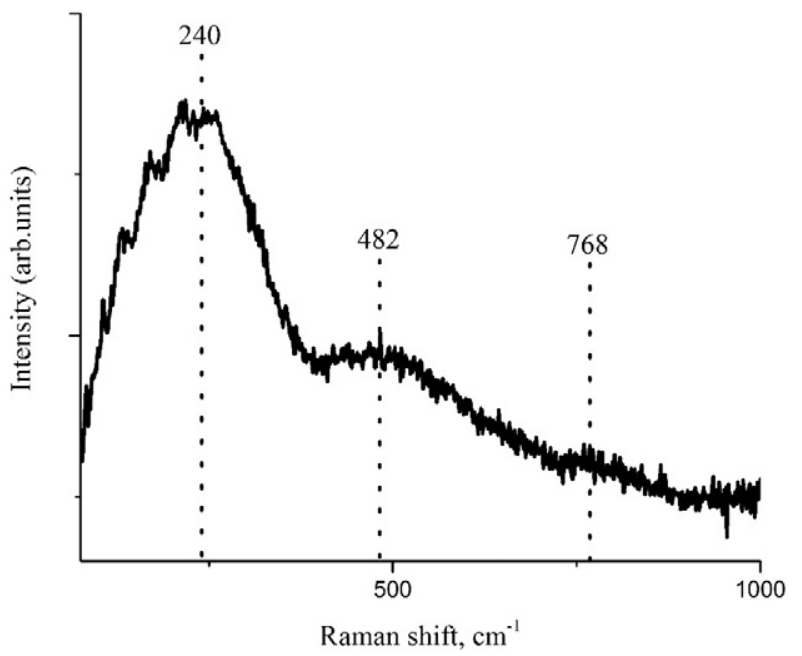

Fig. 8. Raman spectrum of TiAlBSiN coating. acoustic transitions in the $150-300 \mathrm{~cm}^{-1}$ region (LA and TA) and optic modes in the $400-500 \mathrm{~cm}^{-1}$ region (LO and TO) which correlates with the results obtained for TiAlN phase [31,32]. Primarily the vibration of heavy ions near nonmetallic vacancies determines the scattering in the acoustic range, that in the optical range arises from vibration of light atoms adjacent to metallic vacancies. Perfect crystal with fcc structure has $\mathrm{O}_{\mathrm{h}}$ symmetry, every ion is at a site of inversion symmetry and consequently first-order Raman phonon vibrations are forbidden $[33,34]$. However, the effective symmetry of magnetron sputtered coatings is usually reduced, owing to the presence of numerous lattice defects. These defects reduce the effective symmetry [35], as more aluminum is incorporated in the TiN lattice the more likely is the formation of a material with a different structure. Moreover, the additional incorporation of $\mathrm{O}, \mathrm{B}, \mathrm{C}$ or Si atoms in the sublattice of a TiAlN phase, either by substitution of $\mathrm{Al}$ and/or Ti by Si and substitution of $\mathrm{N}$ by $\mathrm{O}$ or/and $\mathrm{C}$ or by occupying interstitial sites, may be another factor that leads to Raman active phonon vibrations. Thus, the Raman spectrum of a perturbed crystal reflects the presence of impurities in the crystal. These indicate that the $\mathrm{Al}$ atoms occupy titanium sites due to the fact that $\mathrm{Al}$ and $\mathrm{Ti}$ have similar atomic radii forming a $(\mathrm{Ti}, \mathrm{Al})(\mathrm{N}, \mathrm{O})$ solid solution. The peak at $768 \mathrm{~cm}^{-1}$ can be attributed to TO phonon mode of $\mathrm{Si}-\mathrm{C}$ that is in agreement with previously published data [36].

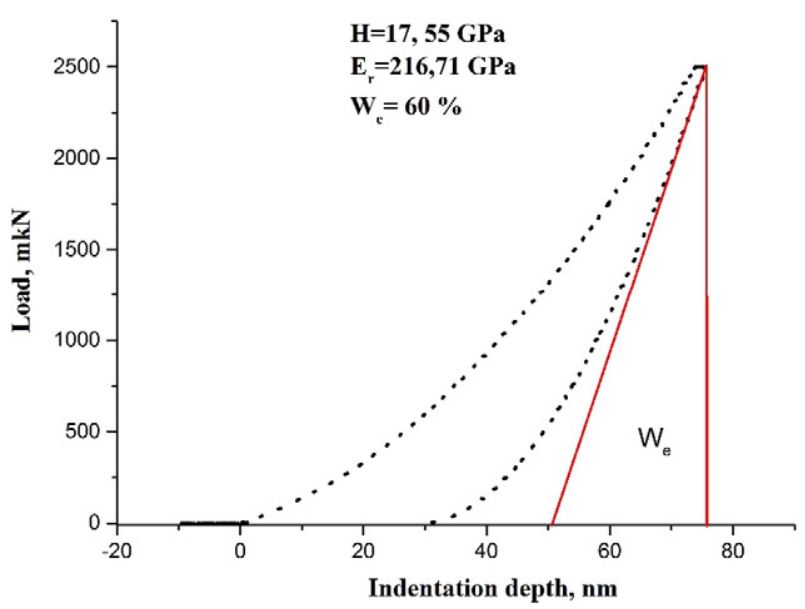

Fig. 9. P-h plot for the TiAlBSiN coating at an indentation depth of $75.5 \mathrm{~nm}$ and maximum load of $2.5 \mathrm{mN}$. 


\subsection{Nanoindentation studies}

Nanoindentation studies of TiAlBSiN coatings deposited on steel substrate were carried out under depth control mode at indentation depth of $75.5 \mathrm{~nm}$ (less than $10 \%$ of coating thickness) at the load $2.5 \mathrm{mN}$. Fig. 9 shows the P-h (load-depth) plot of the TiAlBSiN coating. The hardness $(\mathrm{H})$ and reduced elastic modulus $\left(\mathrm{E}^{*}\right)$ of the TiAlBSiN coating measured from indentation load-displacement data obtained during one cycle of loading and unloading were $17.55 \mathrm{GPa}$ and $216.71 \mathrm{GPa}$, respectively. The relatively low hardness is probably due to the high inter-particle spacing of the nanocrystalline grains and the volume fraction of the amorphous matrix that led to decreasing of the cohesive energy of interface boundaries between the nanocrystalline and amorphous phases.

According to the principle of energy conservation, the total energy expended by the indenter, $W_{\text {total }}$, is transformed into two parts: the elastic recovery energy, $W_{e}$, and the energy dissipation, $W_{d}$ [37]. The areas between the loading and unloading curve represents the energy dissipated in the coating due to the plastic deformation, and the area under the unloading curve represents the elastic energy of deformation. In an indentation loading-unloading cycle, the elastic recovery energy can be determined as $\mathrm{W}_{\mathrm{e}}=\left[\left(\mathrm{h}_{\mathrm{m}}-\mathrm{h}_{\mathrm{f}}\right) / \mathrm{h}_{\mathrm{f}}\right] \times 100$ [38], where $\mathrm{h}_{\mathrm{f}}$ is the final depth after unloading and $\mathrm{h}_{\mathrm{m}}$ is the maximum indentation depth during loading. The TiAlBSiN coating exhibits excellent elastic properties with an elastic recovery energy value up to $60 \%$.

In situ AFM measurements of the residual impressions after nanoindentation experiments were carried out (Fig. 10). The slight pile-up $\sim 10 \mathrm{~nm}$ in height can be found in the region around the indent, no shear bands or radial cracks were observed. It has already been noted by Johnson [39], that a large capacity for work hardening drives the plastic zone into the material to greater depths and decreases the amount of pile-up adjacent to the indenter.

Nanoindentation measurements were conducted using a multiple load function applied to a diamond Berkovich tip with maximum loads from $0.05 \mu \mathrm{N}$ to $10 \mathrm{mN}$ in order to measure hardness $(\mathrm{H})$ and reduced elastic modulus $\left(\mathrm{E}^{*}\right)$ of the TiAlBSiN coating at different depths. The hardness tends to increase with increasing penetration depth and reaches its maximum value $H=18.35 \mathrm{GPa}$ at a depth of $77 \mathrm{~nm}$, Fig. 11a. The average value of hardness was $17.95 \mathrm{GPa}$. The hardness sharply decreases after reaching $10 \%$ of the coating thickness because of the influence of the softer lower layer.

It is demonstrated that not only hardness or elastic modulus but also the ratios $\mathrm{H} / \mathrm{E}^{*}$ and $\mathrm{H}^{3} / \mathrm{E}^{*} 2$ are very important material properties [ 40 , $41,43,44]$. It is commonly known, that wear resistance of a solid can be adjusted by tailoring its elastic-plastic properties. A high $\mathrm{H} / \mathrm{E}^{*}$ ratio is related to a high elastic strain prior to the plastic deformation [42], while purely elastic contact is desired for wear reduction in a tribocontact event between rough surfaces. To predict the wear resistance of the TiAlBSiN coating, the elasticity index $\left(\mathrm{H} / \mathrm{E}^{*}\right)$ was evaluated from data obtained from multiple indentation test and is depicted in Fig. $11 \mathrm{~b}$ as a function of contact depth. The sharp increase of $\mathrm{H} / \mathrm{E}^{*}$ ratio up to 0.088 at a depth of $20 \mathrm{~nm}$ is probably caused by nanoroughness of the coating surface. $\mathrm{H} / \mathrm{E}^{*}$ ratio of the TiAlBSiN coating is varying in the range from 0.08 to 0.09 at the contact depth of $20-75 \mathrm{~nm}$. It is clearly seen that the $\mathrm{H} / \mathrm{E}^{*}$ ratio as well as the hardness start to decrease after a contact depth of $75 \mathrm{~nm}$. It is shown that the values of $\mathrm{H} / \mathrm{E}^{*}$ ratio of TiAlBSiN coating are close to $\mathrm{H} / \mathrm{E}^{*>} 0,1$ which satisfy the condition proposed by Musil [43] for protective nanocomposite coatings and under certain circumstances, the gain from the $\mathrm{H} / \mathrm{E}^{*}$ ratio $0.08-0.09$ in the wear rate reduction could be substantial.

For the practical engineering applications of protective coatings, their hardness should be accompanied by toughness [44]. According to the definition, toughness is the ability of a material to absorb energy during deformation up to fracture [45]. Experiments indicate $[41,44,46$, $47,49]$ that the higher is the toughness of the system coating/substrate as the higher is the $\mathrm{H}^{3} / \mathrm{E}^{* 2}$ ratio (resistance to plastic deformation). It is shown [44] that the resistance of coating to the formation of cracks increases with increasing ratio $\mathrm{H}^{3} / \mathrm{E}^{*} 2$ ratio, i.e. with increasing resistance of the coating to plastic deformation. Therefore, the ratio $\mathrm{H}^{3} / \mathrm{E}^{* 2}$, should be maximized to improve the coating elastic recovery $\mathrm{W}_{\mathrm{e}}$ and its toughness. This means that instead of the coating toughness, the ratio $\mathrm{H}^{3} / \mathrm{E}^{* 2}$ should be used to assess the protective efficiency of the thin film exposed to the external load. The $\mathrm{H}^{3} / \mathrm{E}^{* 2}$ of the coating seemed to play an important role with respect to its erosion wear during abrasive test $[48,49]$. Coatings with high $\mathrm{H}^{3} / \mathrm{E}^{* 2}$ could exhibit lower erosion rates. Fig. $11 \mathrm{~b}$ depicts the resistance to plastic deformation $\left(\mathrm{H}^{3} / \mathrm{E}^{*} 2\right)$ of the TiAlBSiN coating, evaluated at the different indentation depth. $\mathrm{H}^{3} / \mathrm{E}^{* 2}$ ratio increases from 0.01 to the maximum of $0.12 \mathrm{GPa}$ and stay approximately constant up to the depth of $75 \mathrm{~nm}$. No residual deformation was detected after the indentation tests, confirming that the deformation was mainly elastic.

For further investigation of tribological properties of the TiAlBSiN coating, nano-wear test was made using the nanoindenter. The advantage of nano-wear test is that wear properties are mainly determined by the intrinsic properties of the coating materials due to the small loads and scale that allows to exclude the influence of the substrate. Fig. 12 shows typical surface topography of the TiAlBSiN coating after 1 cycle of wear test under a load of $1000 \mu \mathrm{N}$ load in an area of $5 \mu \mathrm{m} \times 5 \mu \mathrm{m}$. The nanowear volume was $352.22 \times 10^{-3} \mu \mathrm{m}^{3}$. Comparative study of nanowear for stainless steel and monocrystalline silicon (100) has been carried out and presented in Table 1. It indicates small material loss and better wear resistance for the TiAlBSiN coating compared to the steel and silicon. Surface height profile in Fig. 12b shows that both the wear scar depth in the range 10 to $15 \mathrm{~nm}$ and the pileup height in the range $\sim 15 \mathrm{~nm}$ to $25 \mathrm{~nm}$ are present at the wear square. The pile-up around the edges of the wear track is probably due to
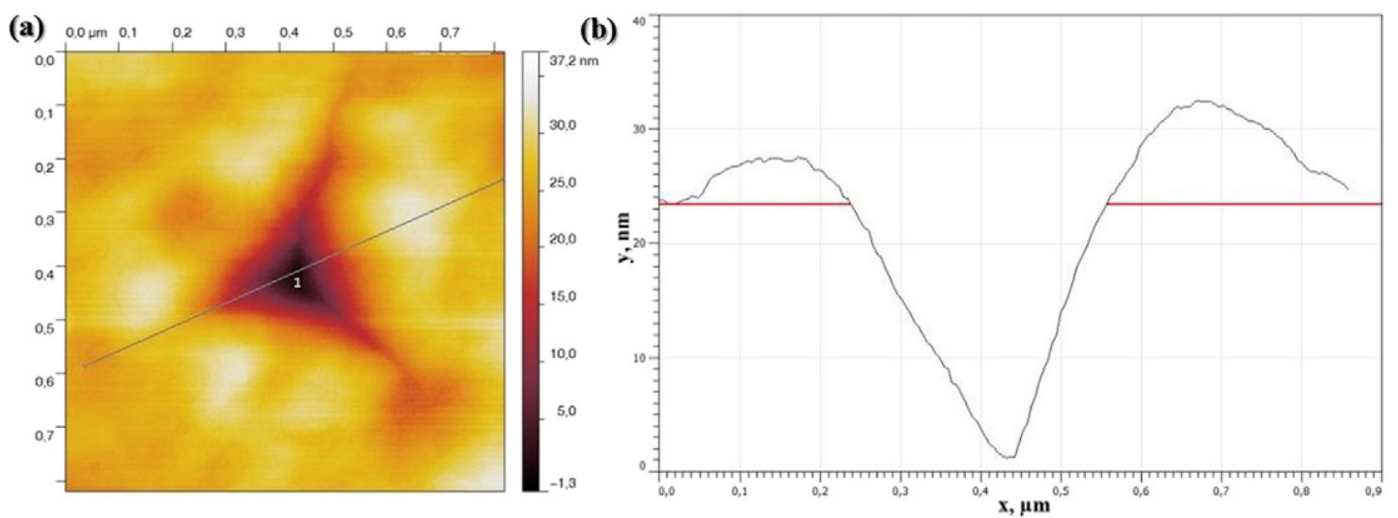

Fig. 10. AFM top view image of the residual impression (a) and the cross-sectional profile of impression (b) after nanoindentation of the TiAlBSiN coating at the load of 2.5 mN. 
(a)

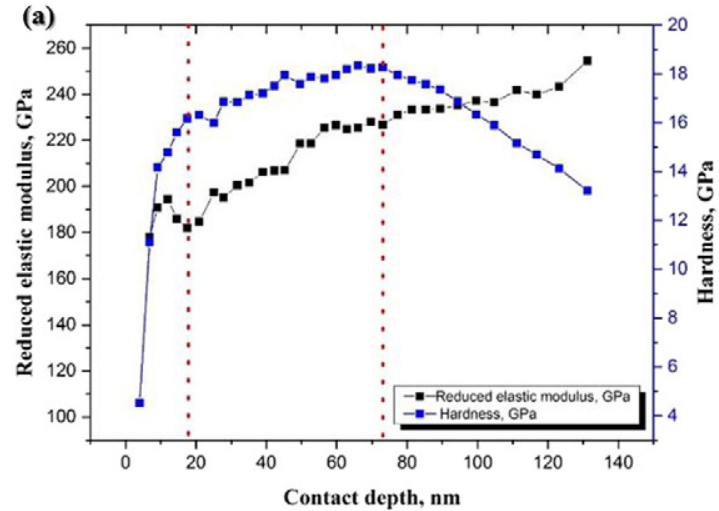

(b)

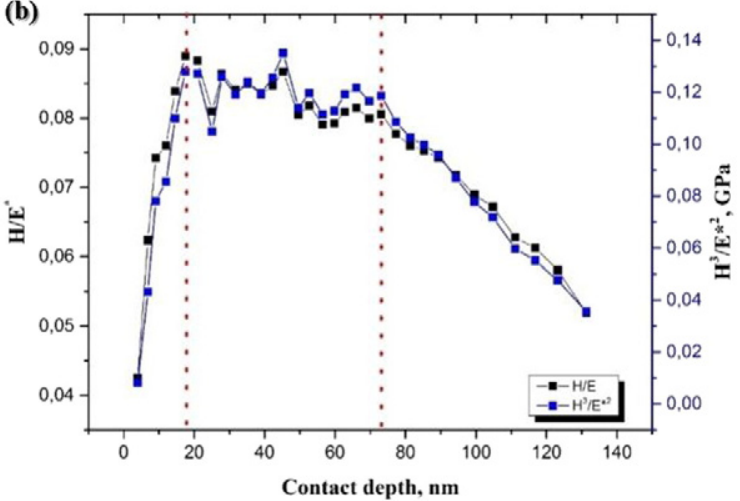

Fig. 11. Hardness and reduced elastic modulus as function of the contact depth (a) and variation of the ratio $\mathrm{H} / \mathrm{E}^{*}$ and $\mathrm{H}^{3} / \mathrm{E}^{* 2}$ as function of contact depth.

indentation in the film normal direction, which often leads to severe plastic deformation indentation in the film normal direction. Further investigation of the wear track using SEM-EDS (Fig. 12c and d) clearly shows that the material loss take palace and wear debris were generated during wear process around the edges of the wear track. Plastic deformation occurs during scratch wear because of the indentation in the film normal direction, while translation along the sliding direction leads to material removal due to abrasive wear and generation of wear debris. For a large wear track, the translation motion dominates and material loss is mainly due to abrasive wear. It is important to note that non-uniform wear of the coating is observed.

It is well known that most metals oxidize in air to some extent and form a number of oxides in form of thin film typically between 1 and $10 \mathrm{~nm}$ thickness. The presence of such oxide ( $\mathrm{Ti}, \mathrm{Al}, \mathrm{Si}) \mathrm{O}_{\mathrm{x}}$ film is confirmed by XPS studies on the surface of TiAlBSiN coating. The oxide film acts as a low shear-strength film during wear and additionally leads to low friction because of low ductility. However, during sliding, these thin oxide films may be penetrated. Furthermore, the film is penetrated at higher loads, and transition occurs to high values of friction. $\mathrm{MeO}_{\mathrm{x}}$ wear debris around the edges of the wear track of TiAlBSiN coating is due to abrasive wear of thin oxide film, but addition oxidation stimulated by the complex chemical and thermal interactions within the sliding contact zone could not be excluded.

\section{Conclusions}

SEM-EDS, AFM, XPS, TEM, Raman spectroscopy and nanoindentation were used for detailed investigation of structure, elemental, phase composition and mechanical properties of magnetron sputtered TiAlBSiN coatings. A two-layer coating was formed via inclusion of $\mathrm{N}_{2}$ in working gas mixture. The studies demonstrated that the TiAlBSiN coating was composed of two layers with different microstructure and elemental
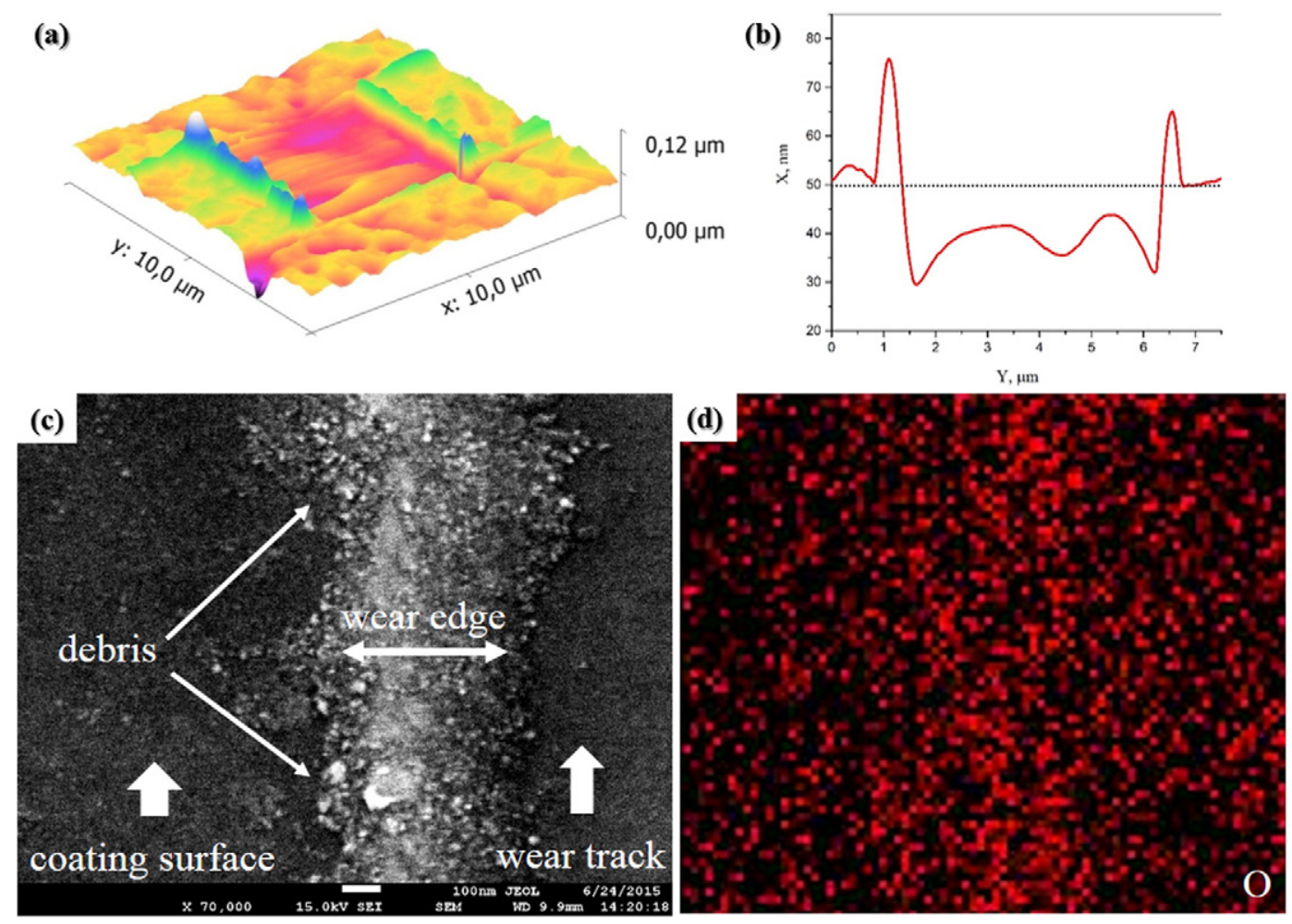

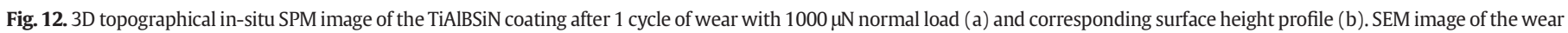
edge with debris (c) and corresponding EDS map of oxygen (d). 
Table 1

Results of tribo-mechanical tests for TiAlBSiN coating, monocrystalline silicon (100) and stainless steel at $1000 \mu \mathrm{N}$ peak load.

\begin{tabular}{lllllll}
\hline Sample & Wear depth, & $\begin{array}{l}\text { Wear volume, } \\
\times 10^{-3} \mu \mathrm{m}^{3}\end{array}$ & $\begin{array}{l}\mathrm{H}, \\
\mathrm{GPa}\end{array}$ & $\begin{array}{l}\mathrm{E}^{*}, \\
\mathrm{GPa}\end{array}$ & $\mathrm{H} / \mathrm{E}^{*}$ & $\mathrm{H}^{3} / \mathrm{E}^{* 2}$ \\
\hline TiAlBSiN & $\sim 15 \mathrm{~nm}$ & 352.22 & 17.55 & 202.7 & 0.087 & 0.1316 \\
Si $(100)$ & $\sim 25 \mathrm{~nm}$ & 502.3 & 12.4 & 189.67 & 0.091 & 0.1449 \\
Stainless steel & $\sim 40 \mathrm{~nm}$ & 2226.72 & 10.30 & 194.38 & 0.053 & 0.0289 \\
\hline
\end{tabular}

composition. High $\mathrm{N}$ content surface layer was formed on the top of layer deposited in non-reactive mode. The inclusion of $\mathrm{N}_{2}$ in the working gas did not cause drastic change of coating structure but only affect the composition of two layers. It was showed that the layers of the TiAlBSiN coating had amorphous/nanocrystalline structure composed of $(\mathrm{Ti}, \mathrm{Al})(\mathrm{N}, \mathrm{O})$ nanograins embedded in the amorphous matrix. The hardness, elastic modulus, elastic recovery $\left(\mathrm{W}_{\mathrm{e}}\right), \mathrm{H} / \mathrm{E}^{*}$ ratio and $\mathrm{H}^{3} / \mathrm{E}^{*} 2$ ratio of TiAlBSiN coating were determined as $17.55 \mathrm{GPa}$, 216.7 GPa, 60\%, 0.08 and $0.12 \mathrm{GPa}$, respectively. Such elastic properties of the TiAlBSiN coating are promising for application of this coating in tools which undergo multiple load-unload impact. These findings satisfying the conditions for protective coatings are of great scientific and practical importance and open a new way in the formation of advanced functional coatings with unique properties, and particularly in the development of protective coatings.

\section{Acknowledgments}

A.P. acknowledges the financial support of Erasmus Mundus EMINENCE partnership. The authors gratefully acknowledge the financial support from the National Centre for Research and Development under research grant "Nanomaterials and their application to biomedicine PBS1/A9/13/2012". The authors are grateful to Dr. B. Scheibe and Dr. B. Peplińska for the help in experiments on Raman spectroscopy and scanning electron microscopy, and Prof. V. M. Beresnev for the help in coating deposition.

\section{References}

[1] H.C. Barshilia, B. Deepthi, K.S. Rajam, K.P. Bhatti, S. Chaudhary, Growth and characterization of TiAlN/CrAlN superlattices prepared by reactive direct current magnetron sputtering, J. Vac. Sci. Technol. A Vac., Surf., Film. 27 (2009) 29, http://dx.doi. org/10.1116/1.3013858.

[2] S. Veprek, M.G.J. Veprek-Heijman, P. Karvankova, J. Prochazka, Different approaches to superhard coatings and nanocomposites, Thin Solid Films 476 (2005) 1-29, http://dx.doi.org/10.1016/j.tsf.2004.10.053.

[3] J. Musil, P. Baroch, J. Vlček, K.H. Nam, J.G. Han, Reactive magnetron sputtering of thin films: present status and trends, Thin Solid Films 475 (2005) 208-218, http://dx.doi. org/10.1016/j.tsf.2004.07.041.

[4] W.F. Piedrahita, L.E. Coy, C. Amaya, I. Llarena, J.C. Caicedo, L. Yate, Influence of the negative R.F. bias voltage on the structural, mechanical and electrical properties of Hf-C-N coatings, Surf. Coat. Technol. 286 (2016) 251-255, http://dx.doi.org/10. 1016/j.surfcoat.2015.12.050.

[5] J. Musil, Hard and superhard nanocomposite coatings, Surf. Coat. Technol. 125 (2000) 322-330, http://dx.doi.org/10.1016/S0257-8972(99)00586-1.

[6] A.D. Pogrebnjak, I.V. Yakushchenko, A.A. Bagdasaryan, O.V. Bondar, R. KrauseRehberg, G. Abadias, et al., Microstructure, physical and chemical properties of nanostructured (Ti-Hf-Zr-V-Nb)N coatings under different deposition conditions, Mater. Chem. Phys. 147 (2014) 1079-1091, http://dx.doi.org/10.1016/j. matchemphys.2014.06.062.

[7] D.-K. Lee, S.-H. Lee, J.-J. Lee, The structure and mechanical properties of multilayer $\mathrm{TiN} /(\mathrm{Ti0} .5 \mathrm{Al0} .5) \mathrm{N}$ coatings deposited by plasma enhanced chemical vapor deposition, Surf. Coat. Technol. 169-170 (2003) 433-437, http://dx.doi.org/10.1016/ S0257-8972(03)00184-1.

[8] C.-L. Chang, J.-W. Lee, M.-D. Tseng, Microstructure, corrosion and tribological behaviors of TiAlSiN coatings deposited by cathodic arc plasma deposition, Thin Solid Films 517 (2009) 5231-5236, http://dx.doi.org/10.1016/j.tsf.2009.03.082.

[9] A.D. Pogrebnjak, A.P. Shpak, V.M. Beresnev, Superhard nanostructured coatings based on Ti-Hf-Si-N thier properties and structure, Nanomater. Appl. Prop. 1 (2011) 212-220.

[10] A.D. Pogrebnjak, D. Eyidi, G. Abadias, O.V. Bondar, V.M. Beresnev, O.V. Sobol, Structure and properties of arc evaporated nanoscale TiN/MoN multilayered systems, Int. J. Refract. Met. Hard Mater. 48 (2015) 222-228, http://dx.doi.org/10.1016/j. ijrmhm.2014.07.043.
[11] G.S. Fox-Rabinovich, I.S. Gershman, K. Yamamoto, A. Biksa, S.C. Veldhuis, B.D. Beake, et al., Self-organization during friction in complex surface engineered tribosystems, Entropy 12 (2010) 275-288, http://dx.doi.org/10.3390/e12020275.

[12] G. Fox-Rabinovich, A. Kovalev, M.H. Aguirre, K. Yamamoto, S. Veldhuis, I. Gershman, et al., Evolution of self-organization in nano-structured PVD coatings under extreme tribological conditions, Appl. Surf. Sci. 297 (2014) 22-32, http://dx.doi.org/10.1016/ j.apsusc.2014.01.052.

[13] W. Lengauer, K. Dreyer, Functionally graded hardmetals, J. Alloys Compd. 338 (2002) 194-212, http://dx.doi.org/10.1016/S0925-8388(02)00232-3.

[14] A.A. Voevodin, J.S. Zabinski, Superhard, functionally gradient, nanolayered and nanocomposite diamond-like carbon coatings for wear protection, Diam. Relat Mater. 7 (1998) 463-467, http://dx.doi.org/10.1016/S0925-9635(97)00214-8.

[15] C. Muratore, A.A. Voevodin, Chameleon coatings: adaptive surfaces to reduce friction and wear in extreme environments, Annu. Rev. Mater. Res. 39 (2009) 297-324, http://dx.doi.org/10.1146/annurev-matsci-082908-145259.

[16] H. Fager, B.M. Howe, G. Greczynski, J. Jensen, A.B. Mei, J. Lu, et al., Novel hard, tough HfAISiN multilayers, defined by alternating Si bond structure, deposited using modulated high-flux, low-energy ion irradiation of the growing film, J. Vac. Sci. Technol. A Vac., Surf., Film. 33 (2015) 05E103, http://dx.doi.org/10.1116/1.4920980.

[17] H. Fager, J.M. Andersson, J. Jensen, J. Lu, L. Hultman, Thermal stability and mechanical properties of amorphous coatings in the Ti-B-Si-Al-N system grown by cathodic arc evaporation from $\mathrm{TiB}_{2}, \mathrm{Ti}_{33} \mathrm{Al}_{67}$, and $\mathrm{Ti}_{85} \mathrm{Si}_{15}$ cathodes, J. Vac. Sci. Technol. A Vac., Surf., Film. 32 (2014) 061508, http://dx.doi.org/10.1116/1.4897170.

[18] J. Musil, S. Kadlec, Reactive to target sputtering distances, Vacuum 40 (1990) 435-444, http://dx.doi.org/10.1016/0042-207X(90)90241-P.

[19] P.H. Mayrhofer, F. Kunc, J. Musil, C. Mitterer, A comparative study on reactive and non-reactive unbalanced magnetron sputter deposition of TiN coatings, Thin Solid Films 415 (2002) 151-159, http://dx.doi.org/10.1016/S0040-6090(02)00511-4.

[20] O.N. Grigor'ev, I.A. Podchernyaeva, A.D. Panasyuk, V.V. Varyukhno, Heat- and wearresistant composite materials and coatings based on $\mathrm{A} 1 \mathrm{~N}-\mathrm{TiB}_{2}$, Refract. Ind. Ceram. 45 (2004) 373-378, http://dx.doi.org/10.1007/s11148-005-0015-4.

[21] D. Rostislav, J. Musil, Novel Nanocomposite Coatings, Pan Stanford Publishing, 2013.

[22] A.A. Onoprienko, V.I. Ivashchenko, I.A. Podchernyaeva, O.Y. Khizhun, I.I. Timofeeva, O.A. Butenko, Production of Ti-Al-Si-B-N films by magnetron sputtering and study of their mechanical properties, Powder Metall. Met. Ceram. 53 (2014) 353-358, http://dx.doi.org/10.1007/s11106-014-9623-1.

[24] D.-C. Tsai, Z.-C. Chang, B.-H. Kuo, C.-T. Tsao, E.-C. Chen, F.-S. Shieu, Influence of discharge power on the structural, electro-optical, and mechanical properties of (TiZrHf)N coatings, J. Alloys Compd. 622 (2015) 446-457, http://dx.doi.org/10. 1016/j.jallcom.2014.10.073.

[25] U. Kroll, Origins of atmospheric contamination in amorphous silicon prepared by very high frequency $(70 \mathrm{MHz}$ ) glow discharge, J. Vac. Sci. Technol. A Vac., Surf., Film. 13 (1995) 2742, http://dx.doi.org/10.1116/1.579698.

[26] F. Kieckow, C. Kwietniewski, E.K. Tentardini, A. Reguly, I.J.R. Baumvol, XPS and ion scattering studies on compound formation and interfacial mixing in TiN/Ti nanolayers on plasma nitrided tool steel, Surf. Coat. Technol. 201 (2006) 3066-3073, http://dx.doi.org/10.1016/j.surfcoat.2006.06.020

[27] C. Wagner, A. Naumkin, A. Kraut-Vass, NIST X-ray photoelectron spectroscopy database, NIST Stand. Ref. Database. 3.3, http://srdata.nist.gov/xps/2003.

[28] D. Jaeger, J. Patscheider, A complete and self-consistent evaluation of XPS spectra of TiN, J. Electron Spectrosc. Relat. Phenom. 185 (2012) 523-534, http://dx.doi.org/10. 1016/j.elspec.2012.10.011

[29] H.A. Castillo, P.J. Arango, J.M. Vélez, E. Restrepo-Parra, G. Soto, W.D.l. Cruz, Synthesis and characterization of cubic BC2N grown by reactive laser ablation, Surf. Coat. Technol. 204 (2010) 4051-4056, http://dx.doi.org/10.1016/j.surfcoat.2010.05.025.

[30] J.G. Speight, Lange's Handbook Of Chemistry, 16th ed., 2005.

[31] H.C. Barshilia, K.S. Rajam, Raman spectroscopy studies on the thermal stability of TiN, CrN, TiAlN coatings and nanolayered TiN/CrN, TiAlN/CrN multilayer coatings, J. Mater. Res. 19 (2004) 3196-3205, http://dx.doi.org/10.1557/JMR.2004.0444.

[32] P.W. Shum, Z.F. Zhou, K.Y. Li, Friction and wear reduction of hard TiAISiN coatings by an integrated approach of laser surface texturing and high-energy ion implantation, Surf. Coat. Technol. 259 (2014) 136-140, http://dx.doi.org/10.1016/j.surfcoat.2014.02.042.

[33] W. Spengler, R. Kaiser, First and second order raman scattering in transition metal compaunds, Solid State Commun. 18 (1976) 881-884

[34] W. Spengler, R. Kaiser, A.N. Christensen, G. Müller-Vogt, Raman scattering, superconductivity, and phonon density of states of stoichiometric and nonstoichiometric TiN, Phys. Rev. B 17 (1978) 1095-1101.

[35] C.P. Constable, J. Yarwood, W.-D. Münz, Raman microscopic studies of PVD hard coatings, Surf. Coat. Technol. 116-119 (1999) 155-159, http://dx.doi.org/10.1016/ S0257-8972(99)00072-9.

[36] J. Wasyluk, T.S. Perova, S.A. Kukushkin, A.V. Osipov, N.A. Feoktistov, S.A. Grudinkin, Raman investigation of different polytypes in SiC thin films grown by solid-gas phase epitaxy on Si (111) and $6 \mathrm{H}-\mathrm{SiC}$ substrates, Mater. Sci. Forum 645-648 (2010) 359-362, http://dx.doi.org/10.4028/www.scientific. net/MSF.645-648.359.

[37] Y.W. Bao, W. Wang, Y.C. Zhou, Investigation of the relationship between elastic modulus and hardness based on depth-sensing indentation measurements, Acta Mater. 52 (2004) 5397-5404, http://dx.doi.org/10.1016/j.actamat.2004.08.002.

[38] J. Musil, F. Kunc, H. Zeman, H. Poláková, Relationships between hardness, Young's modulus and elastic recovery in hard nanocomposite coatings, Surf. Coat. Technol. 154 (2002) 304-313, http://dx.doi.org/10.1016/S0257-8972(01)01714-5.

[39] K.L. Johnson, L.M. Keer, Contact Mechanics, J. Tribol. 108 (1986) 659, http://dx.doi. org/10.1115/1.3261297.

[40] A. Leyland, A. Matthews, On the significance of the $\mathrm{H} / \mathrm{E}$ ratio in wear control: a nanocomposite coating approach to optimised tribological behaviour, Wear 246 (2000) 1-11, http://dx.doi.org/10.1016/S0043-1648(00)00488-9. 
[41] P.K.P. Rupa, P.C. Chakraborti, S.K. Mishra, Structure and indentation behavior of nanocomposite Ti-B-N films, Thin Solid Films 564 (2014) 160-169, http://dx.doi. org/10.1016/j.tsf.2014.05.051.

42] A. Leyland, A. Matthews, Design criteria for wear-resistant nanostructured an glassy-metal coatings, Surf. Coat. Technol. 177-178 (2004) 317-324, http://dx.doi. org/10.1016/j.surfcoat.2003.09.011.

[43] J. Musil, P. Novák, R. Čerstvý, Z. Soukup, Tribological and mechanical properties of nanocrystalline-TiC/a-C nanocomposite thin films, J. Vac. Sci. Technol. A Vac., Surf., Film. 28 (2010) 244, http://dx.doi.org/10.1116/1.3294717.

[44] J. Musil, M. Jirout, Toughness of hard nanostructured ceramic thin films, Surf. Coat Technol. 201 (2007) 5148-5152, http://dx doi.org/10.1016/j.surfcoat 2006.07.020.

[45] S. Zhang, D. Sun, Y. Fu, H. Du, Toughening of hard nanostructural thin films: a critical review, Surf. Coat. Technol. 198 (2005) 2-8, http://dx.doi.org/10.1016/j.surfcoat. 2004.10.020
[46] P.H. Mayrhofer, C. Mitterer, J. Musil, Structure-property relationships in single- and dual-phase nanocrystalline hard coatings, Surf. Coat. Technol. 174-175 (2003) 725-731, http://dx.doi.org/10.1016/S0257-8972(03)00576-0.

[47] J. Guo, H. Wang, F. Meng, X. Liu, F. Huang, Tuning the H/E* ratio and E* of AlN coatings by copper addition, Surf. Coat. Technol. 228 (2013) 68-75, http://dx.doi.org/10. 1016/j.surfcoat.2013.04.008.

[48] J. Deng, F. Wu, Y. Lian, Y. Xing, S. Li, Erosion wear of CrN, TiN, CrAlN, and TiAlN PVD nitride coatings, Int. J. Refract. Met. Hard Mater. 35 (2012) 10-16, http://dx.doi.org/ 10.1016/j.ijrmhm.2012.03.002.

[49] L. Yate, L. Emerson Coy, G. Wang, M. Beltrán, E. Díaz-Barriga, E.M. Saucedo, et al., Tailoring mechanical properties and electrical conductivity of flexible niobium carbide nanocomposite thin films, RSC Adv. 4 (2014) 61355-61362, http://dx.doi. org/10.1039/C4RA11292J. 